\title{
The Marketing Plan for Louis Vuitton's Entry into the Market of Cambodia
}

\author{
Xiaofang Guo \\ School of Finance and Accounting \\ Fuzhou University of International Studies and Trade \\ Fuzhou, China \\ 454184916@qq.com
}

\author{
Li Zhang * \\ School of Finance and Accounting \\ Fuzhou University of International Studies and Trade \\ Fuzhou, China \\ czzhangli@126.com
}

\begin{abstract}
Even if Western economies have not ever been recovered from the financial crisis since 2008 , the luxury sector of high-end is keeping growing. The expansion in this sector has reached more than $10 \%$ in emerging countries. Moreover, luxury products with prestige brands like Louis Vuitton have always continued to penetrate global markets. This paper focuses on designing a marketing mix for Louis Vuitton in Cambodia, which is a developing country with fast growth and increasing tourists. The most valuable luxury brand has not opened the official store in this country. The advantages and methods of operating in Cambodia for $\mathrm{LV}$ would be shown in this article. Moreover, the research could be seen as a proposal for other classic brands to expand their markets in developing countries for more sales.
\end{abstract} Goods

Keywords — Louis Vuitton; Marketing Mix; Cambodia; Luxury

\section{INTRODUCTION}

In recent years, the most famous Luxury brand has opened more than 20 stores in China for owning more market shares in this emerging market. The customers of Asian would prefer to buy the luxury brands in which people around them are familiar. Therefore, Louis Vuitton could expand their market effectively in Asia. As can be seen from the official website of Louis Vuitton, there are two LV stores in Vietnam and one in Thailand. However, the country between these two countries, Cambodia, does not have any Louis Vuitton's official store. This report aims to organize a marketing plan for Louis Vuitton's entering into the market of Cambodia to get an extended market in Asia [1]. The first part would introduce the brand's original country and development history. And the second part would describe the variables of Cambodia to identify why the country is chosen. Furthermore, the specific situations in Cambodia such as demographics, geographics, and psychographics would be shown in the third part. Then the behaviors of potential consumers in Cambodia have been described in the fourth part. Lastly, the marketing mix of the Louis Vuitton's product in Cambodia would be listed to offer advice to the company if it would like to implement the plan to explore the market in reality [2].

\section{A. General Description of France}

France is a sovereign country which includes 18 integral regions (five of them are located overseas) with a total population of approximately 67 million [3]. Paris is the capital of France which is the biggest city and the main center of culture and commerce in this country. France has also been one of the global centers about art, science and fashion. It is a leading tourist destination in the word which have received around 90 million foreign visitors per year. It performs well in international rankings of education, health care and life expectancy with the world's seventh-largest economy in the world in 2018. In France, fashion has become an important industry since the 17th century. Paris has been considered as one of the world's fashion capitals by the fashionista where is the beginning place of modern "haute couture" and the home for many premier fashion houses such as Louis Vuitton, Chanel and Dior.

\section{B. General Description of Louis Vuitton}

Louis Vuitton is one of the oldest and prominent fashion brands in the world. It was founded by Louis Vuitton who was a French box-maker and packer in 1854. From humble beginnings in the French countryside, Louis Vuitton's signature trunks coveted by the world's elite quickly because of his skill, innovation and determination. His decision to becoming a trunk-master that would not only change his own life but his future generations. The products of this house have involved bags, clothing, shoes, accessories and jewelry which has made it become one of the most valuable luxury brands in the world with Marc Jacobs as creative director since 1997 [4]. The product creations of Louis Vuitton have been complex, time-consuming and labor demanding. Many of the brand's products are made of Monogram Canvas materials or Brown Damier which both were first used in the late 19th century. The house has sold its product through its own stores located all over the world which allows the brand to control product quality and pricing. In addition, it also distributes the products through the company's official website in some specific country. The revenue of this company got to around 10 billion in 2017 and has operated in more than 60 countries globally with more than 500 stores in these nations [5].

To sum up, the legendary French brand, Louis Vuitton, should pay more attention in developing countries to get more customers who can consume luxuries whatever they are social elites or just normal people that chasing the arts of exorbitant fashion with their capacity. The marketing planning for Louis Vuitton aims to help the luxury brand getting access into Cambodia to get extended markets in Asia for more sales and more influences. It would aim to update the factors influencing 
consumer purchase of luxury goods in Cambodia. Specifically, the combined effect of 4Ps, brand and country of origin should be considered to attract the customers in Cambodia who are local people or visitors from other countries. The report relates to the possibility of a marketing strategy for the luxury brand with very exclusive and expensive products in a low-income developing country. The income level should be important for consumers making purchasing decisions of luxury goods. However, the reasons why Louis Vuitton can enter into the countries would be analyzed in the following parts. In addition, the plan would propose some management recommendations for Louis Vuitton to expand and market in a suitable way.

\section{General Description of Cambodia}

Cambodia has located in the southern portion of the Indochina peninsula which is 181,035 square kilometers in area with a population of over 15 million. Buddhism is the official religion embraced by approximately 95 percent of the population. The Phnom Penh is the capital and largest city which is also the center of culture, economics and policy. The country is an elected constitutional monarchy with a monarch chosen by the Royal Throne Council as head of the kingdom. And the head of government is the Prime Minister.

The GDP in Cambodia was \$24,572 million in 2018 with ranking 108th in the world. And the GDP grew 7.5\% in 2018 compared to last year. The GDP per capita of Cambodia in 2018 was \$1,512, \$124 higher than in 2017. Cambodia has been one of the fastest-growing economies in Asia with a growing average of $7.6 \%$ over the last decade. The industries of textiles, construction, garments and tourism have gone through strong growth even if agriculture has remained the dominant economic sector.

The demand for luxury goods and experiences, which comes from three aspects, is growing rapidly in Cambodia. The first one is that affluent Cambodians develop a taste for a new lifestyle. In 2018, Cambodian incomes have moved into the World Bank’s Lower-middle Income bracket, passing \$1,380 GNI per capita. Income levels are rising across all socioeconomic classes. Affluent Cambodians are status-conscious to focus on the car, jewelry, handbags, clothing, shoes and mobile phones. And the second aspect is that the number of affluent tourists such as Chinese with powerful purchasing continues to grow. The last one is that some expatriates seek out luxury items. Therefore, there are huge opportunities for luxury brands entering the market of Cambodia to fill the gap in available retail.

The Royal Government of Cambodia welcomes foreign investment and offers investor-focused policies. For example, foreigners can own a company without a joint venture local partner which is suitable for Louis Vuitton's official distribution policy. The tax rates are competitive in the region such as the lowest profit tax rate at $20 \%$. In addition, the government offers some policies about tax exemption for foreign investors such as the "Qualified Investment Project". Furthermore, Cambodia has joined some trade agreements which helps it be in a better international trade environment.

\section{DESCRIPTION OF THE TARGET MARKET}

\section{A. The Increasing Power of Purchasing of Urban Residents}

There are about 20\% people live in urban areas of Cambodia. Moreover, there are about 20\% people live in urban areas of Cambodia. Residents of Phnom Penh have more income than the average Cambodian's income. And the cities such as Battambang, Siem Reap, Sihanoukville and Kampong Cham compose the country's most urban populations except for Phnom Penh. There are also many wealthy people living in these places who can become the potential customers of luxury goods. The Siem Reap has got revenue from the tourism industry. And the tourists passing through have the demand for luxury foods too. Battambang has been known as the rice bowl of Cambodia with the elites acquired their fortunes in the business of agriculture. There are at least some affluent segments of the population in each of these smaller cities who would like to get western goods.

\section{B. The "Face" Focusing}

The people in this country have the desire to own something new and high-quality products even though it is a developing country. The country has been seen a growth in the premium segments despite its small size in the economy. Wealthy consumers are able and willing to pay a premium for luxury consumption. The increasing brand awareness and the growing purchasing power of high net worth consumers dominate further growth of luxury sales. Hence, it is an opportune time for Louis Vuitton to penetrate this country's market.

Most Cambodians think that position and status in society is the most important thing. And the key sign of status is the display of the right brands with them. Specifically, luxury brands have been important for providing "face" just like China. Several Luxury brands like Christofle, Boss and Brioni have already gained a foothold in the Cambodia market. These brands are shaping consumer behavior and building brand loyalty. Louis Vuitton should understand that early entering can shape preferences for its products among its target wealthy consumers in Cambodia and the market is potential.

\section{The Increasing Tourists as Potential Customers}

Furthermore, tourists have been drawn to Cambodia due to its historical attractions, friendly people and cheap consumption. Both tourism receipts and tourism spending have been rising steadily since 2010 in Cambodia and the international tourists have been expected to keep growing through 2019. Cambodia could be a more desirable destination for Chinese rich families and the Western elite if the higherend goods could be offered for tourists.

\section{THE CONSUMER BEHAVIOR IN CAMBODIA}

\section{A. Cambodian Customers}

Cambodian consumers are excited about shopping with more products available for sale in markets because the economy is growing. Materialism is in peoples' hearts to focus on the brands of clothes, cars, bags and accessories. 
Cambodians have looked for products that they know about since their experience with branded products is limited. It should be important for brands that would like to enter into Cambodia to show consumers the values of the brand. The affluent will pay more for the bags of Louis Vuitton because they have learned that it is the most famous luxury brand in this world. Therefore, it would be an advantage for the brand's entering.

Cambodia is a typical youthful country where has included more than $50 \%$ of the population aged under 25 and only $4 \%$ of people aged older than 65. The young are becoming more important in decisions making of consumption. In Phnom Penh, Urban youth congregate on big malls and retailers to decide to choose goods and services for higher quality life. Young Cambodians learn about new products through social media such as Facebook and their friends. They have learnt about new things and told their parents about them. Specifically, daughters give advice on beauty and high-end fashion brands to their mothers. Grown children have sent money home for their families in rural areas and influenced their parents' buying choices. Furthermore, French culture has influenced the older, affluent Cambodians who have pursuit European lifestyle. They have had an interest in expensive French wines, French clothing and trips to Paris for the few who can afford it. It should be accepted by the rich families if there is an opportunity that the legendary Louis Vuitton with history of 150 years appeal to the Cambodian market.

Cambodians are very brand loyal once they have experienced with a product. Products that are easily recognized could have an advantage because they look for a known logo and graphic design. International brands which are famous would be a guarantee of quality in their mind. The affluent people who can afford the price would be likely to return once they have taken the big step of making a purchasing in a namebrand store such as Louis Vuitton.

\section{B. The Consuming of Tourists in Cambodia}

The number of 6.2 million foreign visitors traveled to Cambodia with 11 percent increasing in 2018. The country experienced the third-largest increase in international tourists in ASEAN, behind only Vietnam and Indonesia. In addition, 1.9 million Chinese nationals visited Cambodia which continues to top the list of tourists by nationality in a whopping 70 percent increase. It is expected that there would be at least 3 million Chinese tourists in 2020 by the government. Cambodia is quickly attracting the attention of luxury retailers as its boom of Chinese visitors remains strong. To a certain extent, Cambodia's luxury shopping environment has been transformed by Chinese tourists. Luxury retailers are moving in based on predictions that the number of Chinese visitors will keep increasing in the coming years.

\section{MARKeting MiX Of THE LOUIS VUITTON IN CAMBOdiA}

Louis Vuitton is aggressively expanding its operations in both developed and developed countries. It is helping the company in sales increasing and dependence shifting from saturated developed nations to developing countries. Cambodia should be a suitable target for Louis Vuitton which is in fast economic growth with many foreign tourists of high consumption capacity. Then, how to design the global marketing mix in the characteristic developing country should be considered for Louis Vuitton. The 4P marketing mix would be identified below which include product, pricing, place and promotion [6].

\section{A. Product Strategies}

Louis Vuitton is definitely a global brand which is one of the most valuable brands in the world. The products are offered for stores of Louis Vuitton in many countries and areas. In addition, the position of the products would be the highest fashion with a very high price and preferable quality. Louis Vuitton has made $100 \%$ pure leather products and paid attention to fantastic designs that hard to be imitable. The company registers all its designs and product to avoid imitation. In addition, it has consciously chosen to only make handmade products and not make machine-made. The craftsmen in the company are the finest to ensure the product is unique.

The marketing plan aims for the market of Cambodia. The parts of Cambodians who can afford the higher prices and pursue the well-known luxuries should be considered to identify the suitable product lines in the markets. In addition, duty-free policies should be fought for attracting affluent tourists. The strategy of dual extension would be used by Louis Vuitton for pursuing opportunities outside the home market. It sells exactly the same product with similar advertising and promotion methods just like it has used in France [7].

Product design is a key factor in determining success in global marketing. Generally, Louis Vuitton offers the products of the same designs to the global market such as its classical monogram bags. However, sometimes, a product design that is successful in one world region does meet with success in the rest of the world. This is especially true in the luxury products category. Therefore, the limited edition could be considered with the Cambodian elements could be designed just for the specific group of local customers and tourists who are visiting this country.

\section{B. Pricing Strategies}

It should be a challenge for setting the right price in each country for an international organization. Louis Vuitton's offering should be priced in a very high price. Hence, the pricing strategy of market skimming would be used to focus the customers that are willing to pay a premium for specific products. Louis Vuitton has priced its products based on value rather than price. It offers customers high-value products through its quality and brand. In addition, the high price makes consumers feel that they are exclusive when they carry the products from Louis Vuitton. The main customers in the Cambodian market would be local affluent people and rich tourists who are luxury purchasing for respects from others. And the government should offer some tax-exception policies for luxury retailing. Hence, they can be considered for a suitable pricing strategy. 
preferences and habits of Cambodian are forming and changing rapidly based on this background. The opportunity is existing to introduce typical Louis Vuitton products to the Cambodian for the brand-preference habits forming. In addition, the famous brand which can be known by the Cambodian from the new-tech platforms such as Facebook can already create some demands. Louis Vuitton should take actions quickly to take more market shares against the competitors. Then, product preference of customers would be hard to be changed by other competitors once it established.

Furthermore, although Asian destinations receive the vast majority of outbound Chinese tourists, regional issues can lead to dramatic changes from year to year regarding where this important and high-spending group of travelers decides to visit. The increasing trend of Chinese tourists in Cambodia and relative stable relationships between China and Cambodia can make a specific market for Louis Vuitton in Cambodia.

\section{REFERENCES}

[1] Turunen, Linda Lisa Maria. "Luxury Consumption and Consumption of Luxury Goods.” Interpretations of Luxury, 2017, pp. 61-81.

[2] Riot, Elen. "The Louis Vuitton Foundation.” CSR, Sustainability, and Leadership, Oct. 2017, pp. 237-272.

[3] Hennigs, Nadine, et al. "Consumer Value Perception of Luxury Goods: A Cross-Cultural and Cross-Industry Comparison.” Luxury Marketing, Oct. 2012, pp. 77-99.

[4] “Global Marketing Strategies for the Promotion of Luxury Goods." Advances in Marketing, Customer Relationship Management, and EServices, 2016.

[5] Rosenbloom, Bert. "The Trade Area Mix and Retailing Mix: A Retail Strategy Matrix.” Journal of Marketing, vol. 40, no. 4, 1976, p. 58.

[6] Rancati, Elisa, et al. "Conceptualizing and Measuring Content Marketing in Luxury Firms.” Advances in Marketing, Customer Relationship Management, and E-Services Global Marketing Strategies for the Promotion of Luxury Goods, 2016, pp. 109-132.

[7] Baines, Paul, et al. Marketing. Oxford University Press, 2019. 